\title{
Demand for Nursing Care from Elderly People Hospitalised at an Intensive Care Unit
}

\author{
Mariusz Wysokinski ${ }^{1 *}$, Wieslaw Fidecki ${ }^{1}$, Elzbieta Kowalska ${ }^{2}$, Robert Slusarz ${ }^{4}$, Irena Wronska ${ }^{3}$ Kornelia Kędziora-Kornatowska ${ }^{5}$ and Lilla \\ Walas $^{1}$ \\ ${ }^{1} \mathrm{PhD}$ in Medical Science, Development in Nursing, Medical University of Lublin, Poland \\ ${ }^{2}$ Master of Nursing Science, Development in Nursing, Medical University of Lublin, Poland \\ ${ }^{3}$ Professor, Chair of Development in Nursing, Medical University of Lublin, Poland \\ ${ }^{4} \mathrm{PhD}$ in Medical Science, Neurological and Neurosurgical Nursing Department, Ludwik Rydygier Collegium Medicum in Bydgoszcz, Poland \\ ${ }^{5}$ Professor, Geriatrics Chair and Clinic, Ludwik Rydygier Collegium Medicum in Bydgoszcz, Poland
}

\begin{abstract}
Background: The work aimed at assessing the demand for nursing care from elderly patients at ICUs, based on the TISS-28 scale.

Objective: The research was based on the patients' classification method employing the TISS-28 scale.

Methods: The investigation involved 100 assessment sheets of elderly patients staying at a randomly selected ICU in Lublin from February to April 2010.

Results: Data analysis proved elderly patients' TISS-28 scores were highest for basic activities- 9.31 (SD-2.14), however, lower scores were reported for respiratory therapy 3.45 (SD-1.89). A general TISS-28 assessment for the whole research cohort was 23.64. This means that patients should be provided with nursing care level of one nurse per two patients per shift.

Conclusions: The more advanced the patients' age the lower the assessment of therapeutic interventions within the scope of basic activities and circulation therapy, but at the same time, the higher the assessment of respiratory therapy and other interventions.
\end{abstract}

\section{Keywords: Elderly patients; ICU; TISS- 28 scale}

\section{Introduction}

Intensive Care Units have a special place in the hospital hierarchy. They are places where the number of diagnostic, treatment, care and rehabilitation procedures considerably outnumbers norms drafted for other hospital units. Such procedures are typically undertaken for a patient whose life is threatened and are necessary for sustaining basic vital functions, improving their health state and avoiding complications. Due to specific physiological and pathological changes occurring in organisms, elderly people constitute a specific group of patients hospitalised at ICUs. They may demand a greater care, including a greater nursing care.

This issue has been a focal point for numerous researchers, who have been employing various methods to investigate it. One of the tools proposed to investigate this phenomenon is the TISS-28, the scale formed on the basis of the TISS scale, which was drafted in 1974 as a method for quantitative assessment of medical interventions for the sake of a patient [1].

No research has yet been undertaken based on this tool that would attempt at assessing elderly patients' demand for nursing care when hospitalised at ICUs. Hence this investigation may be considered innovative and give rise to a discussion focusing on this group of patients.

\section{Aim of the Work}

This work aimed at attempting to assess the demand for nursing care from elderly people hospitalised at Intensive Care Units on the basis of the TISS- 28 scale.

\section{Material and Methods}

The TISS-28 scale consists of seven theme blocks. They refer to activities undertaken for the sake of a patient at ICUs. These include: monitoring basic functions, supporting and/ or substituting respiratory functions, supporting renal functions, monitoring actions of the central nervous system, treating metabolic disorders and intervening actions undertaken for the sake of a patient at an Intensive Care Unit and outside [2]. A maximum that a patient may score on the TISS-28 scale corresponds to approximately 10 minutes of direct care of a patient during a single nursing shift; therefore a nurse during her single shift may undertake actions that correspond to $40-50$ points. Authors of the TISS-28 recommend calculating scores once per a nursing shift [3]

Based on the score system existing for that scale, the following classification of patients has been drafted to specify patients' demand for nursing care:

- in category IV, one nurse takes care of one patient ( $\geq 40$ points)

- in category III, one nurse takes care of two patients $(>20-39$ points)

- in category II, one nurse takes care of four patients $(>10-19$ points)

- in category I, many patients may be ascribed to one nurse $(<10$ points) [4].

${ }^{*}$ Corresponding author: Mariusz Wysokinski, Chair of Development in Nursing Medical University of Lublin, Al. Raclawickie 1, 20-095 Lublin, Poland, Tel: +48 081-532-27-47; Fax: +48-081-532-27-47, E-mail: mariuszwysokinski@interia.pl

Received December 27, 2011; Accepted January 29, 2012; Published February 02,2012

Citation: Wysokinski M, Fidecki W, Kowalska E, Slusarz R, Wronska I, et al. (2012 Demand for Nursing Care from Elderly People Hospitalised at an Intensive Care Unit. J Nurs Care 1:105. doi:10.4172/2167-1168.1000105

Copyright: @ 2012 Wysokinski M, et al. This is an open-access article distributed under the terms of the Creative Commons Attribution License, which permits unrestricted use, distribution, and reproduction in any medium, provided the original author and source are credited. 
Approval having been obtained from the head of the hospital, the research was administered at the anaesthesiology and intensive care unit of the District Railway Hospital in Lublin from February to April 2010 and 100 observations of elderly patients were performed at that time on the basis of the TISS-28 scale. Investigations were carried out on a daily basis at 7:00 am. Research results were marked on specially prepared TISS-28 forms.

Statistical analysis of measurable parameters' values was presented by means of the average value, median and standard deviation, and for non-measurable values by means of the amount and proportion. The U Mann-Whitney test was used to compare two independent groups. The Kruskal-Wallis test was used for more than two groups. The $\mathrm{R}$ Spearman correlation was used to investigate an association between two values. The $\mathrm{p}<0.05$ relevance level was adapted that indicated existence of statistically significant differences and dependencies. STATISTICA 8.0 (StatSoft, Poland) computer software was the basis for creating the database and carrying out the statistical analysis.

Assessment of the demand for nursing care in the cohort of investigated patients comprised of 60 males and 40 females was made by evaluating their state on the basis of the TISS- 28 scale. They were people whose age ranged from 65 to 72 years. For the sake of this paper, they were divided into two age groups- i.e. patients below 70 years of age and patients older than 70 . The majority of observation sheets, i.e. $60 \%$ were from patients with urban background and the further $40 \%$ were from patients with rural background. In the investigated cohort, major hospitalisation causes included: circulation and respiratory insufficiency (40.00\%), thrombotic phlebitis (10.00\%), sepsis $(20.00 \%)$, multi-focal inflammatory changes in the brain (20.00\%), multi-organ injury (10.00\%).

\section{Research Results}

Therapeutic interventions recognised on the TISS- 28 scale, such as standard monitoring and diuresis measurements were undertaken for $100 \%$ of investigated patients. Other interventions that were undertaken with considerable frequency included: administering numerous medicines $(90.0 \%)$, respiratory physiotherapy $(80.0 \%)$, enteral feeding (79.0\%), respiration support (60\%), extra-intestine feeding $(60 \%)$, forced diuresis (59\%), laboratory tests (58\%), administering a single medicine $(40.0 \%)$ and nursing artificial respiratory tract $(40.0 \%)$. Interventions undertaken with considerably lower frequency included: frequent dressing changes (25/0\%), drainage nursing $(21.0 \%)$, administering a single vasoactive medicine (21.0\%), mechanical ventilation (21.0\%), arterial catheter $(20.0 \%)$ and central vein catheter (20.0\%). Interventions undertaken most rarely included: standard dressing (15.0\%), activities outside ICUs (13.0\%), single interventions at ICUs (8.0\%), ICP measurements (3\%). Treatment of tissue acidosis/ alkalosis and numerous interventions at ICUs were undertaken sporadically $(1.0 \%)$. Therapeutic interventions which never occurred during the study of the elderly cohorts included: treatment with durfaktan, treatment with nitrogen oxide, hemofiltration, resuscitation dialysis, pulmonary vein catheter, treatment of massive liquid loss and administering numerous vasoactive medicines.

Analysing data proved that TISS-28 scores of elderly patients were highest within the scope of basic activities - 9.31 (SD- 2.14), while lowest scores were registered for the following interventions: respiratory therapy 3.45 (SD- 1.89), treatment supporting renal functions- 3.77 (SD- 1.48), supporting metabolism- 3.42 (SD- 1.50), and circulation therapy 2.60 (SD- 3.90). For the "other interventions" criterion the value averaged out at 0.94 (SD- 1.84) and for monitoring activity of the central nervous system it was 0.15 (SD-0.16).
During the research an average number of points patients scored at the ICU were also assessed depending on the number of days of they stay, their age, gender, place of residence and major medical diagnosis.

$23 \%$ of assessments of people from the investigated cohort referred to a 1-7 day stay and the average number of TISS score for this period was 23.91.21 observation sheets referred to patients staying at intensive care on $8^{\text {th }}$ to $14^{\text {th }}$ day. In this case the TISS- 28 score averaged out at 27.48. $20 \%$ referred to $15^{\text {th }}$ to $21^{\text {st }}$ day of stay, and the average score was 27.50. In case of $22^{\text {nd }}$ to $28^{\text {th }}$ day of hospitalisation (10\%), the score averaged out at 21.60. The average score was lowest for those staying for more than 28 days ( $26 \%$ of observation sheets) - 18.12 .

Statistical analysis of the material allowed to discover statistically significant differences depending on the number of the days of stay at the ICU in assessing demand for therapeutic interventions such as: circulation therapy, treatment supporting excretory renal functions, supporting metabolism, other interventions and the general TISS28 assessment, however, no statistically significant differences were discovered for other interventions, $(p>0.05)$ (Table 1). Correlation analysis exhibited a statistically significant negative correlation for the group of elderly patients between the number of their days of stay, assessing basic activities, circulation therapy, treatment supporting renal functions, supporting metabolism, treatment supporting excretory renal functions, other interventions and a general TISS-28 assessment. This means that the longer a stay at the ICU, the smaller the assessment of the demand for the abovementioned interventions from elderly patients (Table 2).

Analysing the research material within the scope of investigated patients' age, it was found that the TISS-28 assessment was higher in the age group of up to 70 years of age (averagely 27.90 points) than patients older than 70 (averagely 20.80 points). Administered research proved patients up to 70 years of age to score statistically lower within the scope of basic functions, circulation therapy, treatment supporting excretory renal functions and the general TISS assessment than patients over 70 years of age. Patients over 70 years of age scored significantly lower within the scope of respiratory therapy, however, no significant differences were found in supporting metabolism, other interventions and monitoring activity of the central nervous system, $(p>0.05)$ (Table 1). Statistical analysis proved there was a significant negative correlation in the group of elderly patients between the age and assessment of basic functions and supporting metabolism, and a positive correlation with respiratory therapy $(\mathrm{R}=0.77)$ and other interventions $(\mathrm{R}=0.26)$, however, no significant correlation was found with the circulation therapy, treatment supporting excretory renal functions, monitoring activity of the central nervous system and a general TISS- 28 assessment. The analysis helped to discover a significant negative correlation in the group of elderly patients. The higher the patients' age the lower the assessment of therapeutic interventions within the scope of basic functions and circulation therapy, but the higher their assessment within the scope of respiratory therapy and other interventions (Table 2).

Analysing the next variable- investigated patients' gender, it was found that elderly males had slightly higher TISS-28 scores (averagely 26.35 points) in comparison with females (averagely 21.83 points). Statistical analysis exhibited statistically significant differences in assessing basic functions among elderly males and females and in assessing respiratory therapy, circulation therapy and in supporting metabolism. However, in other intervention assessments differences were not statistically significant $(\mathrm{p}>0.05)$. Basic actions, circulation therapy and supporting metabolism obtained higher scores in males (Table 1). 
Citation: Wysokinski M, Fidecki W, Kowalska E, Slusarz R, Wronska I, et al. (2012) Demand for Nursing Care from Elderly People Hospitalised at an Intensive Care Unit. J Nurs Care 1:105. doi:10.4172/2167-1168.1000105

Page 3 of 5

\begin{tabular}{|c|c|c|c|c|c|c|c|c|c|c|}
\hline & \multicolumn{8}{|c|}{ Therapeutic interventions according to the TISS-28 scale } \\
\hline & & & 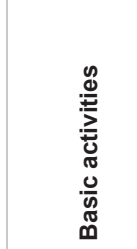 & 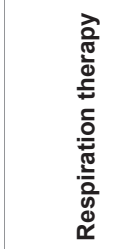 & 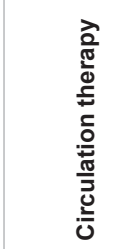 & 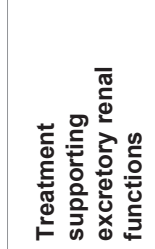 & 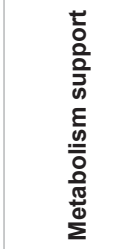 & 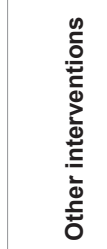 & 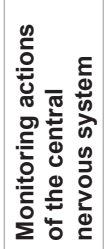 & 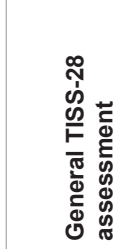 \\
\hline \multirow{8}{*}{ 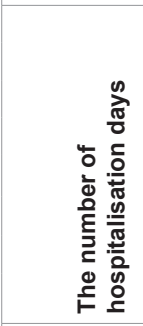 } & \multirow{2}{*}{$1-7$} & $\chi$ & 9.17 & 3.22 & 3.43 & 4.87 & 3.22 & 0.00 & 0.00 & 23.91 \\
\hline & & SD & 1.87 & 1.57 & 4.55 & 0.63 & 1.65 & 0.00 & 0.00 & 5.78 \\
\hline & \multirow{2}{*}{$8-14$} & $\chi$ & 9.24 & 4.00 & 4.33 & 5.00 & 4.00 & 0.67 & 0.24 & 27.48 \\
\hline & & SD & 3.28 & 2.21 & 4.29 & 0.00 & 1.45 & 1.46 & 1.09 & 5.67 \\
\hline & \multirow{2}{*}{$15-21$} & $\chi$ & 9.80 & 4.00 & 4.05 & 3.95 & 4.50 & 0.70 & 0.50 & 27.50 \\
\hline & & SD & 1.85 & 2.51 & 4.20 & 1.47 & 1.43 & 1.49 & 1.54 & 10.20 \\
\hline & \multirow{2}{*}{ Over 21 days } & $\chi$ & 9.17 & 2.97 & 0.25 & 2.25 & 2.61 & 1.83 & 0.00 & 19.08 \\
\hline & & SD & 1.59 & 1.32 & 0.84 & 0.84 & 0.87 & 2.37 & 0.00 & 4.16 \\
\hline \multirow{2}{*}{$\begin{array}{l}\text { Statistical } \\
\text { analysis }\end{array}$} & $\mathrm{H}$ & & 3.20 & 1.60 & 26.13 & 65.21 & 24.03 & 13.96 & 5.36 & 29.18 \\
\hline & $\mathrm{p}$ & & 0.36 & 0.66 & $0.0001^{*}$ & $0.0001^{*}$ & $0.0001^{*}$ & $0.003^{*}$ & 0.15 & $0.0001^{*}$ \\
\hline \multirow{4}{*}{ 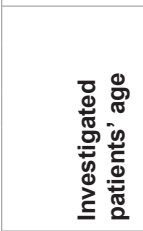 } & \multirow{2}{*}{ Up to 70 years old } & $\chi$ & 10.73 & 2.63 & 5.00 & 4.93 & 3.55 & 0.70 & 0.37 & 27.90 \\
\hline & & SD & 1.52 & 0.87 & 5.06 & 0.47 & 1.81 & 1.47 & 1.33 & 8.08 \\
\hline & \multirow[b]{2}{*}{ Over 70 years old } & $\chi$ & 8.37 & 4.00 & 1.00 & 3.00 & 3.33 & 1.10 & 0.00 & 20.80 \\
\hline & & SD & 1.97 & 2.18 & 1.43 & 1.43 & 1.26 & 2.04 & 0.00 & 5.14 \\
\hline \multirow{2}{*}{$\begin{array}{l}\text { Statistical } \\
\text { analysis }\end{array}$} & z & & -5.87 & 2.53 & -2.81 & -5.42 & 0.00 & 0.52 & -0.63 & -4.62 \\
\hline & $\mathrm{p}$ & & $0.000001^{*}$ & $0.01^{*}$ & $0.005^{*}$ & $0.000001^{*}$ & 1.00 & 0.60 & 0.53 & $0.000004^{*}$ \\
\hline \multirow{4}{*}{ 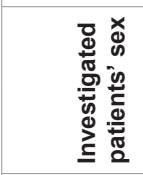 } & \multirow{2}{*}{ Females } & $\chi$ & 8.50 & 4.33 & 1.00 & 3.95 & 2.97 & 1.08 & 0.00 & 26.35 \\
\hline & & SD & 2.06 & 1.90 & 1.43 & 1.44 & 1.47 & 2.08 & 0.00 & 4.70 \\
\hline & \multirow{2}{*}{ Males } & $\chi$ & 10.53 & 2.13 & 5.00 & 3.50 & 4.10 & 0.73 & 0.38 & 21.83 \\
\hline & & SD & 1.63 & 0.79 & 5.06 & 1.52 & 1.28 & 1.40 & 1.33 & 9.50 \\
\hline \multirow{2}{*}{$\begin{array}{l}\text { Statistical } \\
\text { analysis }\end{array}$} & z & & 4.80 & -8.09 & 2.81 & -1.27 & 4.29 & -0.30 & 0.63 & 1.51 \\
\hline & $\mathrm{p}$ & & $0.000002^{*}$ & $0.000001^{*}$ & $0.005^{\star}$ & 0.21 & $0.00002^{*}$ & 0.77 & 0.53 & 0.13 \\
\hline \multirow{4}{*}{ 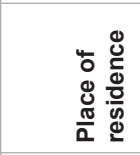 } & \multirow{2}{*}{ Urban } & $\chi$ & 9.35 & 3.75 & 4.33 & 4.00 & 4.40 & 0.57 & 0.25 & 26.65 \\
\hline & & SD & 2.43 & 2.40 & 4.23 & 1.43 & 1.12 & 1.32 & 1.10 & 7.87 \\
\hline & \multirow{2}{*}{ Rural } & $\chi$ & 9.25 & 3.00 & 0.00 & 3.42 & 1.95 & 1.50 & 0.00 & 19.13 \\
\hline & & SD & 1.63 & 0.00 & 0.00 & 1.52 & 0.32 & 2.32 & 0.00 & 2.78 \\
\hline \multirow{2}{*}{$\begin{array}{l}\text { Statistical } \\
\text { analysis }\end{array}$} & z & & -1.42 & 2.53 & -5.63 & -1.62 & -8.44 & 1.46 & -0.42 & -4.34 \\
\hline & $\mathrm{p}$ & & 0.16 & $0.01^{*}$ & $0.000001^{*}$ & 0.11 & $0.000001^{*}$ & 0.14 & 0.67 & $0.00001^{*}$ \\
\hline \multirow{8}{*}{ 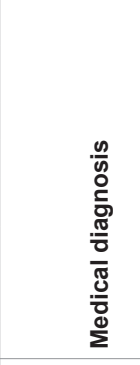 } & \multirow{2}{*}{ Thrombotic phlebitis } & $\chi$ & 10.50 & 3.00 & 0.00 & 4.85 & 1.90 & 0.25 & 0.00 & 20.50 \\
\hline & & SD & 1.47 & 0.00 & 0.00 & 0.67 & 0.45 & 1.12 & 0.00 & 2.31 \\
\hline & \multirow{2}{*}{ Sepsis } & $\chi$ & 10.10 & 2. 00 & 0.00 & 2.00 & 3.00 & 0.30 & 0.00 & 17.40 \\
\hline & & SD & 1.62 & 0.00 & 0.00 & 0.00 & 0.00 & 0.92 & 0.00 & 1.85 \\
\hline & \multirow{2}{*}{$\begin{array}{l}\text { Multi-focal inflammatory } \\
\text { changes in the brain }\end{array}$} & $\chi$ & 10.10 & 2.00 & 0.00 & 2.00 & 3.00 & 0.30 & 0.00 & 17.40 \\
\hline & & SD & 1.62 & 0.00 & 0.00 & 0.00 & 0.00 & 0.92 & 0.00 & 1.85 \\
\hline & Circulation and respiratory & SD & 8.97 & 4.63 & 6.50 & 5.00 & 5.10 & 0.70 & 0.38 & 31.27 \\
\hline & insufficiency & $\chi$ & 2.69 & 2.53 & 3.54 & 0.00 & 0.63 & 1.47 & 1.33 & 5.12 \\
\hline Statistical & $\mathrm{H}$ & & 29.85 & 32.06 & 92.81 & 95.11 & 97.95 & 21.40 & 4.59 & 77.86 \\
\hline analysis & $\mathrm{p}$ & & $0.0001^{*}$ & $0.0001^{*}$ & $0.001^{*}$ & $0.001^{*}$ & $0.001^{*}$ & $0.0001^{*}$ & 0.20 & $0.0001^{*}$ \\
\hline
\end{tabular}

$\chi-$ median

$\mathrm{SD}$ - statistical deviation

Table 1: Assessment of therapeutic interventions according to the TISS-28 scale depending on the variables being analysed.

Assessment of therapeutic interventions in the cohort comprised of elderly patients was higher for those with urban background (averagely 26.65 points) than for those with rural background (averagely 19.13 points). According to the findings of this research, elderly patients with urban background scored significantly more highly in interventions concerning: respiratory therapy, circulation therapy, supporting metabolism and a TISS general assessment than patients with the rural background. No significant differences were found in assessments of basic functions, treatment supporting excretory renal functions, other interventions and monitoring activities of the central nervous system (Table 1). 
Elderly patients with circulation \& respiratory insufficiency obtained highest average TISS-28 scores- 31.27 , whereas the lowest average score was obtained by those with multi-focal encephalitis17.75. The score for patients suffering from sepsis averaged out at 17.40, and for those with thrombotic phlebitis it was 20.50 points. Performing statistical analysis allowed discovering significant differences in assessing all therapeutic interventions, except monitoring the activities of the central nervous system. All interventions, except basic activities were found to obtain a higher average score from patients with circulation \& respiratory insufficiency (Table 1).

Investigated patients were classified into respective care categories on the basis of the TISS- 28 scale. A general assessment based on the TISS-28 scale for the whole research cohort averaged out at 23.64. This means that elderly patients hospitalised at investigated ICUs ought to be provided with the nursing care at the level of one nurse per two patients per shift. Having analysed respective state assessment sheets, it was found that $63 \%$ of all cases were ascribed to category III of the nursing care (i.e. where one nurse is needed per two patients), $33.0 \%$ of the total number were ascribed to category II (one nurse per four patients per shift). Merely $3.0 \%$ were ascribed to category IV of the nursing care (one nurse per one patient), and $1 \%$ to category I of the nursing care.

\section{Discussion}

None of the accessible databases features a large number of investigations that might make a reference point for discussing the findings that were obtained. They are merely an attempt at answering the question concerning a demand for patients with special needs, i.e. elderly patients hospitalised at Polish Intensive Care Units, employing the TISS-28 scale, which is widely used for these purposes [5]. Shortage of research results by other authors is one of the major limitations of this work. Moreover, the authors realise that the research cohort is rather small and located in a single healthcare unit. However, this work is hoped to trigger a discussion on elderly patients' presence at intensive care units. Furthermore, this investigation may be a reference point for similar studies employing other research tools allowing an evaluation of patients' demand for nursing care, e.g. the NEMS scale (Nine Equivalents of Nursing Manpower Use Score) and/ or the NAS scale (Nursing Activities Score). Additionally, a comparison of findings from various organisation systems might prove interesting as it may reveal differences in the range of care provided to elderly people in various countries.
Undertaking this investigation proved that the majority of activities were undertaken within the scope of basic activities. Activities connected with supporting respiration and renal functions were placed in further places. Similar results were obtained in the research undertaken in New Zealand, where $97.78 \%$ of patients aged over 65 were provided with oxygen therapy and $75.11 \%$ had the work of their hearts monitored [4]. Similar results were also recorded from elderly patients hospitalised at Finnish ICUs, e.g. with respect to arterial catheters or haemodialysis, which was rarely administered for the benefit of these patients [6]. In comparison with patients hospitalised in Hong-Kong, criteria such as: laboratory tests, administering numerous vasoactiove medicines, mechanical ventilation, also scored more rarely. On the other hand, scoring more often referred to events such as a single administration of a vasoactive medicine, enteral feeding, and respiratory physiotherapy [7]. In case of average values obtained for individual criteria of the scale, higher average values were obtained for two criteria, i.e. the treatment supporting excretory renal functions and supporting metabolism, however, for other five criteria they were lower than those in the research findings referred to above [7].

A general TISS-28 scale averaged out at 23.64. Other findings were obtained for Polish ICUs by other authors, however, not for elderly patients, whose average TISS- 28 scores exceeded 30 points and even came close to 40 points [5,8]. Nevertheless, the score is higher than that for elderly patients hospitalised at Spanish Intensive Care Units, where scores ranged from 18.7 to 20.5 point on the TISS- 28 scale [9], but lower than for elderly patients at Finnish ICUs, where scores ranged from 25.3 to 28.3 TISS-28 points [6]. Considering the number of points scored in the group of elderly patients, the greatest number of patients was classified to the category III of the nursing care according to the TISS-28 scale. It means that they needed nursing staff at the level of one nurse per two patients per shift in order to be provided with optimum nursing care. Similar results were obtained for patients from the units of South-Eastern Poland [10]. However, it must be pointed out that within the research cohort, patients over 70 years of age were significantly more often classified into category I or category II of nursing carte in comparison with patients below 70 years of age.

Performing the statistical analysis allowed to exhibit a significant negative correlation for elderly patients between the numbers of days of their stay and assessing basic activities, circulation therapy, treatment supporting renal functions, supporting metabolism, treatment supporting excretory renal functions, other interventions

\begin{tabular}{|c|c|c|c|c|c|c|c|c|c|}
\hline \multirow{2}{*}{\multicolumn{2}{|c|}{ 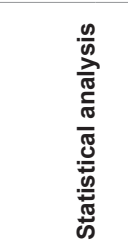 }} & \multicolumn{8}{|c|}{ Therapeutic interventions according to the TISS- 28 scale } \\
\hline & & \multirow{2}{*}{ 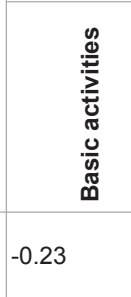 } & \multirow{2}{*}{ 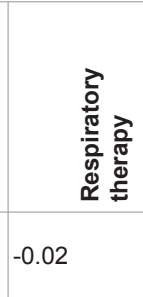 } & \multirow{2}{*}{ 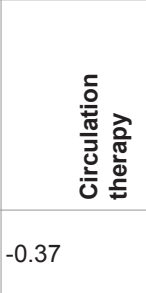 } & \multirow{2}{*}{ 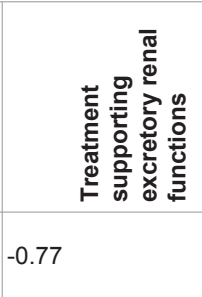 } & \multirow{2}{*}{ 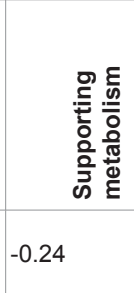 } & \multirow{2}{*}{ 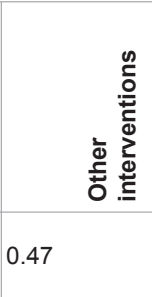 } & \multirow{2}{*}{ 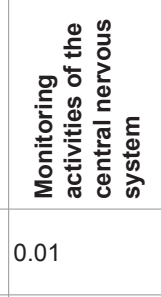 } & \multirow{2}{*}{ 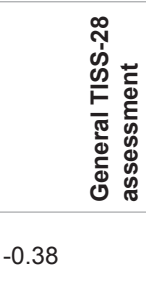 } \\
\hline 을 & $\mathrm{R}$ & & & & & & & & \\
\hline 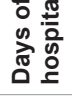 & $\mathrm{p}$ & $0.02^{*}$ & 0.82 & $0.0001^{*}$ & 0. $000001^{*}$ & $0.02^{*}$ & $0.000001^{*}$ & 0.93 & $0.00008^{*}$ \\
\hline \multirow{2}{*}{ 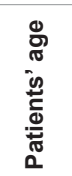 } & $\mathrm{R}$ & -0.62 & 0.77 & -0.11 & 0.00 & -0.31 & 0.26 & -0.12 & -0.05 \\
\hline & $\mathrm{p}$ & $0.000001^{*}$ & $0.000001^{*}$ & 0.27 & 1.00 & $0.001^{*}$ & $0.01^{*}$ & 0.22 & 0.63 \\
\hline
\end{tabular}

SD - standard deviation

Table 2: Assessment of the correlation between therapeutic interventions for elderly patients with the number of the days of stay. 
and a general TISS-28 scale assessment. The longer the stay the smaller the assessment of the demand for the aforementioned interventions. The greater patients' age the smaller the assessment of therapeutic interventions within the scope of basic actions and the circulation therapy, but at the same time, the greater the assessment of respiration therapy and other interventions. Significant differences were found in the assessment of basic activities and the assessment of the respiration therapy, circulation therapy and supporting metabolism depending on investigated patients' gender. However, differences were not statistically significant in other intervention assessments. The basic activities, circulation therapy and supporting metabolism obtained worse assessments in case of males. It was also found that all interventions, except basic functions, obtained worse assessments for patients with circulation and respiratory insufficiency.

\section{Conclusions}

1. It was interventions from the group of basic functions that were undertaken most often for elderly patients, while actions connected with supporting respiration and supporting renal functions were undertaken slightly more rarely.

2. In the cohort of elderly patients, the greatest number of patients was placed in category III, which means they demanded nursing care at the level of one nurse per two patients per shift.

3. The more advanced patients' age the smaller the assessment of therapeutic interventions within the scope of basic activities and circulation therapy, but at the same time the greater the assessment of respiration therapy and other interventions.

4. Patients with circulation and respiration insufficiency and sepsis were found to have the greatest demand for care in the cohort of elderly people.
5. In the cohort comprised of elderly patients, basic actions, circulation therapy and supporting metabolism obtained worse assessments in case of males.

\section{References}

1. Wojtas M (2003) the use of the TISS-28 and the NEMS scales in direct calculation of demand for the nursing care. The 3rd Convention of the Anesthesiology and Intensive Care Nurses' Association. 2003: 72-93.

2. Keene AR, Cullen DJ (1983) Therapeutic Intervention Scoring System: Update 1983. Crit Care Med 11: 1-3.

3. Miranda DR, de Rijk A, Schaufeli W (1996) Simplified Therapeutic Intervention Scoring System: the TISS-28 items - results from a multicenter study. Crit Care Med 24: 64-73.

4. Pirret AM (2002) Utilizing TISS to differentiate between intensive care and highdependency patients and identify nursing skill requirements. Intensive Crit Care Nurs 18: 19-26.

5. Gój K, Knapik P, Kucewicz-Czech E, Luboń D (2009) The TISS-28 scoring system for assessment of cardiac surgical postoperative intensive care. Anestezjol Intens Ter 41: 37-40.

6. Reinikainen M, Uusaro A, Niskanen M, Ruokonen E (2007) Intensive care of the elderly In Finland. Acta Anaesthesiol Scand 51: 522-529.

7. Yee Kwok WW, Chun Chau JP, Pau Le Low L, Thompson DR (2005) The reliability and validity of the therapeutic activity index. J Crit Care 20: 257-263.

8. Cudak-Banska E, Dyk D, Zadroga M, Krysiak I, Gabryszak M (2005) Quantitative assessment of intensive care unit nurses' workload based on the TISS-28 (Simplified Therapeutic Intervention Scoring System - 28) and the NEMS (Nine Equivalent of Nursing Manpower Score) scales. Intensive and Critical Medicine. 8: 137-143.

9. Torres OH, Francia E, Longobardi V, Gich I, Benito S, et al. (2006) Short- and long-term outcomes of older patients in intermediate care units. Intensive Care Med 32: 1052-1059.

10. Wysokinski M, Ksykiewicz-Dorota A, Fidecki W (2010) Demand for nursing care for patients in intensive care units in Southeast Poland. Am J Crit Care 19: 149-155. 